\title{
Fuzzy Eoq Model for Time-Dependent Deteriorating Items And Time-Dependent Demand with Shortages
}

\author{
Sumana Saha ${ }^{1}$, Tripti Chakrabarti ${ }^{2}$ \\ 1,2 Department of Applied Mathematics, University of Calcutta, 92 A.P.C. Road, Calcutta-700009, INDIA.
}

\begin{abstract}
In this paper, We discuss a fuzzy EOQ model for time-dependent deteriorating items and timedependent demand with shortages. We consider here an EOQ model in which inventory is depleted not only by demand, but also by deterioration. This paper deals with infinite time horizon fuzzy Economic Order Quantity (EOQ) models for weibull deteriorating items with time dependent exponential demand rate. We have taken deterioration parameter $\beta_{0}$ as a triangular fuzzy number $\left(\beta_{0}-\delta_{1}, \beta_{0}, \beta_{0}+\gamma_{2}\right)$, where $0<\delta_{1}, \delta_{2}<\beta_{0}$ are fixed real numbers. The traditional parameters such as unit cost ,ordering cost and holding cost have been kept constant. The approximate optimal solution for the fuzzy profit functions have been obtained and numerical example is provided to illustrate the solution procedure for the developed fuzzy EOQ model. Finally, Sensitivity of the optimal solution to changes in the values of some key parameters is also studied.
\end{abstract}

Keywords: EOQ Model, Shortages with partially backlogging, Weibull Distribution, exponential Demand rate, Fuzzy Deterioration.

\section{Introduction}

In inventory management, many researchers have studied inventory models for deteriorating items such as volatile liquids, blood banks, medicines, electronic components and fashion goods. The effect of deterioration is very important in many inventory systems. Deterioration is defined as decay or damage such that the item cannot be used for its original purpose. Most of the physical goods undergo decay or deterioration over time. Commodities such as fruits, vegetables, foodstuffs, etc., suffer from depletion by direct spoilage while kept in store. Highly volatile liquids such as gasoline, alcohol, turpentine, etc., undergo physical depletion over time through the process of evaporation. Electronic goods, radioactive substances, photographic film, grain, etc. deteriorate through a gradual loss of potential or utility with the passage of time. Thus decay or deterioration of physical goods in stock is a very realistic feature and inventory modelers felt the need to take this factor into consideration. Since the development of the EOQ concept more than four decades ago T.M. Whitin [1], a substantial amount of researches have been conducted in this area of inventory lot sizing. Constant demand rate is not always suitable to many inventory items such as electric goods, fashionable clothes, tasty foods, etc. as they experience fluctuations in the demand rate. In the last few years, the inventory lot-sizing models with timevarying demand and deterioration have received considerable attention. U. Dave and L.K. Patel [2] first considered the inventory models for deteriorating items with linear increasing demand. The consideration of exponentially decreasing demand for deteriorating items was first analyzed by H. Hollier and K.L. Malc [3]. H. $\mathrm{Xu}$ and $\mathrm{H}$. Wang [4] proposed, 'Optimal inventory policy for perishable items with time proportional demand'. A. Goswami and K.S. Chaudhuri [5] established, "An EOQ model for deteriorating items with shortages and a linear trend in demand". We know that the shortages in inventory systems are either completely backlogged or totally lost. T.Chakrabarti [6] developed an EOQ model for deteriorating items with a linear trend in demand and shortages in all cycles .However, it is more reasonable to characterize that the longer the waiting for the next replenishment, the smaller the backlogging rate would be for many products with growing sales. The length of waiting time for the replenishment is the main factor for determining whether the backlogging will be accepted or not, and the backlogging rate is expected to be time dependent. T.Chakrabarti [7] considered an EOQ model for items with Weibull distribution deterioration, shortages and trended demand: An extension of Phillip's model. H.J. Chang and C.Y. Dye [8] developed an EOQ model for deteriorating items with time-varying demand and partial backlogging. Teng et al., [9] who proposed an optimal recursive method for various inventory replenishment model with increasing demand and shortages also considered this area. M. Valliathal and R. Uthayakumar [10] developed an EOQ model for perishable items under stock and time-dependent selling rate with shortages. In reality, products deteriorate continuously such as medicines, volatile liquids and others. $\mathrm{H}$. Yan and T. Cheng [11] developed an Optimal production stopping and restarting times for an EOQ model with deteriorating Items. S.K. Goyal and B.C. Giri [12] presented a survey on "Recent trends in model of deteriorating inventory," which is more helpful to the researchers who are working in deteriorating items.

In the development economic production lot size models, usually researchers consider the deterioration rate, demand rate, unit cost and production rate as fixed, but all of them probably will have some little disturbances for each cycle in real life situation. So in practical situations, if these quantities are treated as fuzzy 
variables then it will be more realistic. T.K. Roy and M. Maiti [13] presented a fuzzy EOQ model with demand dependent unit cost under limited storage capacity. Chang et al [14] presented a fuzzy inventory model with backorder, where the backorder quantity was fuzzified as the triangular fuzzy number. H.M. Lee and J.S. Yao [15] fuzzified the demand quantity and production quantity per cycle and D.C. Lin and J.S. Yao [16] fuzzified the production quantity per cycle, treating them as triangular fuzzy numbers. S. De and A. Goswami [17] presented the EOQ model with fuzzy deterioration rate. G.C. Mahata and A. Goswami [18] has used fuzzy concepts to develop a fuzzy EOQ model with stock-dependent demand rate and non-linear holding cost by taking rate of deterioration to be a triangular fuzzy number.

In this paper, we first consider a deterministic inventory model weibull deteriorating items with timedependent demand where unsatisfied demand is partially backlogged. Then we develop the corresponding fuzzy EOQ model for fuzzy deteriorating items with exponential demand rate under partial backlogging. The total profit in fuzzy sense is derived. The deterioration rate is fuzzified as the triangular fuzzy number . The fuzzy model is defuzzified by using the extension principle [19]. The solutions for maximizing the fuzzy profit functions have been derived by using the techniques of H. J. Zimmerman [19] and A. Kaufmann and M. M. Gupta [20]. The approximate optimal solutions for the model have been obtained by a numerical example. This paper is organized as follows: In section 2, we describe in brief the notations and assumptions used in the developed model. In section 3 we present the mathematical model and in section 4 we present the corresponding Fuzzy model \& solution procedures. In section 5, numerical examples are given to illustrate the model. In section 6, Sensitivity analysis have been made for different changes in the parameter values. Finally, conclusions are given in section 7 .

\section{Assumptions and Notations}

The following notations and assumptions are being used to develop the Mathematical model:

2.1 Notations

$\mathrm{K}$ the ordering cost per order

$\mathrm{P} \quad$ the purchase cost per unit

$\mathrm{P}^{\prime} \quad$ the selling price per unit, where $\mathrm{P}^{\prime}>\mathrm{P}$

$\theta(\mathrm{t}) \quad$ the deterioration rate

h the holding cost per unit per unit time

d the deterioration cost per unit per unit time

$\mathrm{s} \quad$ the shortage cost per unit per unit time

$\pi \quad$ the opportunity cost due to lost sales per unit

$\mathrm{I}(\mathrm{t}) \quad$ the inventory level at time $\mathrm{t}$, where $\mathrm{t} \in[0, \mathrm{~T}]$

$\mathrm{R}(\mathrm{t}) \quad$ the demand rate at time $\mathrm{t}$, where $\mathrm{t} \in[0, \mathrm{~T}]$

$\delta \quad$ the backlogging parameter, where $0 \leq \delta \leq 1$

$\mathrm{T}$ the length of the replenishment cycle

$\mathrm{T}_{1} \quad$ the time at which the shortages starts, $0 \leq \mathrm{T}_{1} \leq \mathrm{T}$

$\mathrm{TP}$ the total inventory profit per unit time.

\subsection{ASSUMPTIONS}

The proposed model is developed under the following assumptions:

(i) The replenishment rate is infinite and lead time is zero.

(ii) The distribution of time to deterioration of the items follows weibull distribution with arameters $\beta$ and $\gamma$,i.e. $\theta(\mathrm{t})=\beta \gamma \mathrm{t}^{\gamma-1} \quad ; \quad 0<\beta<1, \gamma>0, \mathrm{t}>0$

(iii) The demand rate function $\mathrm{R}(\mathrm{t})$ follows exponential distribution with parameters $\mathrm{a}$ and $\mathrm{b}$, i.e. $\quad \mathrm{R}(\mathrm{t})=\mathrm{a} \mathrm{e} \mathrm{e}^{\mathrm{bt}} \quad ; \quad 0<\mathrm{b}<1, \mathrm{t}>0, \mathrm{a}>0$

(iv) The unit cost and the inventory carrying cost are known and constant.

(v) The selling price per unit and the ordering cost per order are known and constant.

(vi) Shortages are allowed and unsatisfied demand is backlogged at the rate of $\frac{1}{[1+\delta(\mathrm{T}-\mathrm{t})]}$. The backlogging parameter $\delta$ is a positive constant and $\mathrm{T}_{1} \leq \mathrm{t} \leq \mathrm{T}$.

(vii) There is no repair or replacement of the deteriorated items during the production cycle .

\section{Model Formulation}

Using the above assumptions, the inventory level follows the pattern depicted in Fig. 1. It is assumed that the inventory level at time $t=0$ is $Q$. The depletion of the inventory occurs due to the combined effects of the demand and deterioration in the interval $\left[0, \mathrm{~T}_{1}\right)$ and the demand backlogged in the interval $\left[\mathrm{T}_{1}, \mathrm{t}\right)$. 


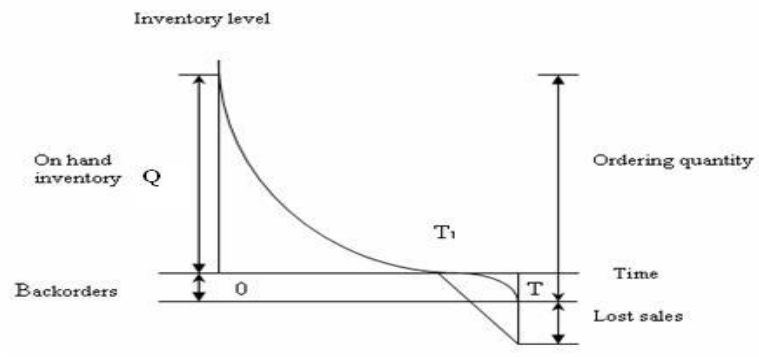

Fig.1 Graphical representation of inventory system.

Hence, The instantaneous states of the inventory level $\mathrm{I}(\mathrm{t})$ at time $\mathrm{t}(0 \leq \mathrm{t} \leq \mathrm{T})$ can be described by the following differential equations :

$\begin{aligned} \frac{\mathrm{d}(\mathrm{t})}{\mathrm{dt}}+\beta \gamma \mathrm{t}^{\gamma-1} \mathrm{I}(\mathrm{t}) & =-\mathrm{a} \mathrm{e}^{\mathrm{bt}} & ; & 0 \leq \mathrm{t} \leq \mathrm{T}_{1} \\ \frac{\mathrm{dI}(\mathrm{t})}{\mathrm{dt}} & =-\frac{\mathrm{a} \mathrm{e}^{\mathrm{bt}}}{[1+\delta(\mathrm{T}-\mathrm{t})]} & ; & \mathrm{T}_{1} \leq \mathrm{t} \leq \mathrm{T}\end{aligned}$

with boundary condition $\mathrm{I}(0)=\mathrm{Q}, \quad \mathrm{I}\left(\mathrm{T}_{1}\right)=0$

The solutions of the above differential equation 1 and equation 2 using equation 3 are given respectively as

$\mathrm{I}(\mathrm{t})=\mathrm{a} \mathrm{e}^{-\beta \mathrm{t}^{\gamma}}\left[\left(T_{1}-t\right)+\frac{b}{2}\left(T^{2}-t^{2}\right)+\frac{\beta}{\gamma+1}\left(T^{\gamma+1}-t^{\gamma+1}\right)+\frac{\beta b}{\gamma+2}\left(T_{1}^{\gamma+2}-t^{\gamma+2}\right)\right] \quad ; 0 \leq \mathrm{t} \leq \mathrm{T}_{1}$

$\mathrm{I}(\mathrm{t})=-\int_{t}^{T_{1}} \frac{a e^{b u}}{[1+\delta(T-u)]} d u \quad ; \quad \mathrm{T}_{1} \leq \mathrm{t} \leq \mathrm{T}$

From equation $4, \mathrm{I}(0)=\mathrm{Q}$ gives

$\mathrm{Q}=\mathrm{a} T_{1}\left(1+\frac{b}{2} T_{1}+\frac{\beta}{\gamma+1} T_{1}^{\gamma}+\frac{\beta b}{\gamma+2} T_{1}^{\gamma+1}\right)$.

The profit per unit time of this model consists of the following elements :

$>\quad$ the setup cost per cycle $\mathrm{K}$

$>\quad$ the holding cost per cycle (HC)

$>\quad$ the deterioration cost per cycle(DC)

$>\quad$ the shortage cost per cycle (SC)

$>\quad$ the opportunity cost due to lost sales per cycle (OC)

$>\quad$ the purchase cost per cycle $\left(\mathrm{PC}_{1}, \mathrm{PC}_{2}\right)$

$>\quad$ the sales revenue per cycle (SR)

The holding cost for carrying inventory over the period $\left[0, \mathrm{~T}_{1}\right]$ is

$$
\begin{aligned}
\mathrm{HC} & =\int_{0}^{T_{1}} h I(t) d t \\
& =a h T_{1}^{2}\left[\frac{1}{2}+\frac{b T_{1}}{3}-\frac{\beta T_{1}^{\gamma}}{\gamma+1}\left\{\frac{\gamma}{\gamma+2}+\frac{b T_{1} \gamma}{\gamma+3}+\frac{b T_{1}^{\gamma+1}}{2 \gamma+3}\right\}\right]
\end{aligned}
$$

The deterioration cost per cycle during the period $\left[0, T_{1}\right]$ is

$$
\begin{aligned}
\mathrm{DC} & =\mathrm{d}\left[\mathrm{Q}-\int_{0}^{\mathrm{T}_{1}} \mathrm{a} \mathrm{e}^{\mathrm{bt}} \mathrm{dt}\right] \\
& =\mathrm{d} \beta \mathrm{aT}_{1}^{\gamma+1}\left(\frac{1}{\gamma+1}+\frac{b T_{1}}{\gamma+2}\right) .
\end{aligned}
$$

The shortage cost over the period $[\mathrm{T}, \mathrm{T}]$ is

$$
\begin{aligned}
\mathrm{SC} & =s \int_{T_{1}}^{T}[-I(t)] d t \\
& =s \int_{T_{1}}^{T}\left\{-\int_{t}^{T_{1}} \frac{a e^{b u}}{[1+\delta(T-u)]} d u\right\} d t \\
& =a s\left[\frac{1}{2}\left(T-T_{1}\right)^{2}-\frac{b}{2}\left(T T_{1}^{2}-4 T_{1}^{3}-\frac{T^{3}}{3}\right)+\frac{b \delta}{12}\left(6 T^{2} T_{1}^{2}-8 T T_{1}^{3}-T^{4}+3 T_{1}^{4}\right)\right]
\end{aligned}
$$

The opportunity cost due to lost sales during the period $\left[\mathrm{T}_{1}, \mathrm{~T}\right]$ is

$$
\begin{aligned}
\mathrm{OC} & =\pi \int_{T_{1}}^{T} a e^{b t}\left[1-\frac{1}{[1+\delta(T-t)]}\right] d t \\
& =\pi \delta \int_{T_{1}}^{T} \frac{a e^{b t}(T-t)}{[1+\delta(T-t)]} \mathrm{dt} \\
& =\pi \delta a\left[\frac{\left[T-T_{1}\right)^{2}}{2}+b\left(\frac{T^{3}}{6}-\frac{T T_{1}^{2}}{2}+\frac{T_{1}^{3}}{3}\right)\right]
\end{aligned}
$$


The purchase cost during the period $\left[0, \mathrm{~T}_{1}\right]$ is

$\mathrm{PC}_{1}=P a\left[T_{1}+\frac{b T_{1}^{2}}{2}+\frac{\beta}{\gamma+1} T_{1}^{\gamma+1}+\frac{\beta b}{\gamma+2} T_{1}^{\gamma+2}\right]$

and the purchase cost during the period $\left[\mathrm{T}_{1}, \mathrm{~T}\right]$ is

$$
\begin{aligned}
\mathrm{PC}_{2} & =\int_{T_{1}}^{T} \frac{P a e^{b t}}{[1+\delta(T-t)]} d t \\
& =\frac{P a}{b}\left(e^{b T}-e^{b T_{1}}\right)\left(1-\delta T-\frac{\delta}{b}\right)+\frac{P a \delta}{b}\left(T e^{b T}-T_{1} e^{b T_{1}}\right)
\end{aligned}
$$

The sales revenue over the period $[0, \mathrm{~T}]$ is

$$
\begin{aligned}
\mathrm{SR} & =P^{\prime} \int_{0}^{T_{1}} a e^{b t} d t+P^{\prime} \int_{T_{1}}^{T} \frac{a e^{b t}}{[1+\delta(T-t)]} d t \\
& =\frac{P^{\prime} a}{b}\left[e^{b T_{1}}-1\right]+\frac{P^{\prime} a}{b}\left(e^{b T}-e^{b T_{1}}\right)\left(1-\delta T-\frac{\delta}{b}\right)+\frac{P^{\prime} a \delta}{b}\left(T e^{b T}-T_{1} e^{b T_{1}}\right)
\end{aligned}
$$

Therefore, the total profit per unit time during the period $[0, \mathrm{~T}]$ is given by

$$
\begin{aligned}
& \mathrm{TP}\left(\mathrm{T}_{1}, \mathrm{~T}\right)=\frac{1}{T}\left[S R-K-H C-D C-S C-O C-P C_{1}-P C_{2}\right] \\
&= \frac{1}{T}\left[\left\{\frac{P^{\prime} a}{b}\left(e^{b T_{1}}-1\right)+\frac{P^{\prime} a}{b}\left(e^{b T}-e^{b T_{1}}\right)\left(1-\delta T-\frac{\delta}{b}\right)+\frac{P^{\prime} a \delta}{b}\left(T e^{b T}-T_{1} e^{b T_{1}}\right)\right\}-K-a h T_{1}^{2}\left\{\frac{1}{2}+\frac{b T_{1}}{3}-\right.\right. \\
&\left.\frac{\beta T_{1}^{\gamma}}{\gamma+1}\left(\frac{\gamma}{\gamma+2}+\frac{b T_{1} \gamma}{\gamma+3}+\frac{b T_{1}^{\gamma+1}}{2 \gamma+3}\right)\right\}-\mathrm{d} \beta \mathrm{aT} \mathrm{T}_{1}^{\gamma+1}\left(\frac{1}{\gamma+1}+\frac{b T_{1}}{\gamma+2}\right)-a s\left\{\frac{1}{2}\left(T-T_{1}\right)^{2}-\frac{b}{2}\left(T T_{1}^{2}-4 T_{1}^{3}-\frac{T^{3}}{3}\right)+\frac{b \delta}{12}\left(6 T^{2} T_{1}^{2}-\right.\right. \\
& \\
&\left.\left.\quad 8 T T_{1}^{3}-T^{4}+3 T_{1}^{4}\right)\right\}-\pi \delta a\left\{\frac{\left(T-T_{1}\right)^{2}}{2}+b\left(\frac{T^{3}}{6}-\frac{T T_{1}^{2}}{2}+\frac{T_{1}^{3}}{3}\right)\right\}-P a\left(T_{1}+\frac{b T_{1}^{2}}{2}+\frac{\beta}{\gamma+1} T_{1}^{\gamma+1}+\frac{\beta b}{\gamma+2} T_{1}^{\gamma+2}\right)- \\
&\left.\left\{\frac{P a}{b}\left(e^{b T}-e^{b T_{1}}\right)\left(1-\delta T-\frac{\delta}{b}\right)+\frac{P a \delta}{b}\left(T e^{b T}-T_{1} e^{b T_{1}}\right)\right\}\right]
\end{aligned}
$$

The solutions for the optimal values of $\mathrm{T}_{1}$ and $\mathrm{T}$ (say $\mathrm{T}_{1}^{*}$ and $\mathrm{T}^{*}$ ) can be found by solving the following equations simultaneously:

$$
\frac{\partial \mathrm{TP}\left(\mathrm{T}_{1}, \mathrm{~T}\right)}{\partial \mathrm{T}}=0 \quad \text { and } \quad \frac{\partial \mathrm{TP}\left(\mathrm{T}_{1}, \mathrm{~T}\right)}{\partial \mathrm{T}_{1}}=0
$$

Provided they satisfy the conditions :

$$
\left[\frac{\partial^{2} T P\left(T_{1}, T\right)}{\partial T_{1}^{2}}\right]_{a t\left(T_{1}^{*}, T^{*}\right)}<0,\left[\frac{\partial^{2} T P\left(T_{1}, T\right)}{\partial T^{2}}\right]_{a t\left(T_{1}^{*}, T^{*}\right)}<0
$$

and $\quad\left[\left[\frac{\partial^{2} T P\left(T_{1}, T\right)}{\partial T_{1}^{2}}\right]\left[\frac{\partial^{2} T P\left(T_{1}, T\right)}{\partial T^{2}}\right]-\left[\frac{\partial^{2} T P\left(T_{1}, T\right)}{\partial T_{1} T}\right]^{2}\right]_{a t\left(T_{1}^{*}, T^{*}\right)}>0$.

Here our problem is to determine the optimal values $\mathrm{T}_{1}^{*}$ and $\mathrm{T}^{*}$ which maximizes the TP.

Maximize $\mathrm{TP}\left(T_{1}, T\right)=\mathrm{f}\left(T_{1}, T\right)+\beta g\left(T_{1}, T\right) \quad ; \quad \mathrm{T}_{1}, \mathrm{~T}>0$

Where

$\mathrm{f}\left(T_{1}, T\right)=\frac{1}{T}\left[\left\{\frac{P^{\prime} a}{b}\left[e^{b T_{1}}-1\right]+\frac{P^{\prime} a}{b}\left(e^{b T}-e^{b T_{1}}\right)\left(1-\delta T-\frac{\delta}{b}\right)+\frac{P^{\prime} a \delta}{b}\left(T e^{b T}-T_{1} e^{b T_{1}}\right)\right\}-K-a h T_{1}^{2}\left\{\frac{1}{2}+\right.\right.$ $\left.\frac{b T_{1}}{3}\right\}-a s\left\{\frac{1}{2}\left(T-T_{1}\right)^{2}-\frac{b}{2}\left(T T_{1}^{2}-4 T_{1}^{3}-\frac{T^{3}}{3}\right)+\frac{b \delta}{12}\left(6 T^{2} T_{1}^{2}-8 T T_{1}^{3}-T^{4}+3 T_{1}^{4}\right)\right\}-\pi \delta a\left\{\frac{\left(T-T_{1}\right)^{2}}{2}+\right.$

$\left.\left.b\left(\frac{T^{3}}{6}-\frac{T T_{1}^{2}}{2}+\frac{T_{1}^{3}}{3}\right)\right\}-\left\{P a\left(T_{1}+\frac{b T_{1}^{2}}{2}\right)\right\}-\left\{\frac{P a}{b}\left(e^{b T}-e^{b T_{1}}\right)\left(1-\delta T-\frac{\delta}{b}\right)+\frac{P a \delta}{b}\left(T e^{b T}-T_{1} e^{b T_{1}}\right)\right\}\right]$

and

$g\left(T_{1}, T\right)=\frac{1}{T}\left[\left\{\frac{a h T_{1}^{\gamma+2}}{\gamma+1}\left(\frac{\gamma}{\gamma+2}+\frac{b T_{1}^{\gamma}}{\gamma+3}+\frac{b T_{1}^{\gamma+1}}{2 \gamma+3}\right)\right\}-\operatorname{daT}_{1}^{\gamma+1}\left(\frac{1}{\gamma+1}+\frac{b T_{1}}{\gamma+2}\right)-\left\{P a T_{1}^{\gamma+1}\left(\frac{1}{\gamma+1}+\frac{b T_{1}}{\gamma+2}\right)\right\}\right]$

\section{Fuzzy Model And Solution Procedure}

Usually researchers consider different parameters of an inventory model either as constant or dependent on time or probabilistic in nature for the development of the EOQ model. But, in real life situations, these parameters may have little deviations from exact value, which may not follow any probability distribution. In these situations, if these parameters are treated as fuzzy parameters, then it will be more realistic. These types of problems are defuzzified first using suitable fuzzy technique and then the solution procedure can be obtained in the usual manner.

considered the deterioration rate, unit cost and ordering cost as fixed, but all of them probably will have some little disturbances for each cycle in the real situation. Hence these parameters should be treated as fuzzy variables. The effect of deterioration is very important aspect of inventory systems. Deterioration refers to decay 
Fuzzy Eoq Model For Time-Dependent Eteriorating Items And Time-Dependent Demand With

or damage or spoilage or vaporized such that the item can not be used for its original purpose. Food items, drugs, pharmaceuticals, radioactive substances, etc. are examples of that kind of items. In the above developed crisp model ,deterioration rate was treated as dependent on time. But in real life situations, they will fluctuate little from the actual values. Let us take deterioration rate as fuzzy in nature by introducing the parameter $\beta$ as the triangular fuzzy numbers .

When the deterioration rate becomes fuzzy, the function of equation 15 can be redefined as

Maximize $\mathrm{TP}\left(T_{1}, T\right)=\mathrm{f}\left(T_{1}, T\right)+\widetilde{\beta} g\left(T_{1}, T\right) \quad ; \quad \mathrm{T}_{1}, \mathrm{~T}>0$

(wavy bar $(\sim)$ denotes the fuzzification of the parameters.)

We express the parameter $\beta$ as the triangular fuzzy number $\left(\beta_{0}-\delta_{1}, \beta_{0}, \beta_{0}+\delta_{2}\right)$. Suppose, the membership function of the fuzzy number $\widetilde{\beta}$ is as follows

$\mu_{\tilde{\beta}}(\beta)=\left\{\begin{array}{cl}\frac{\beta-\beta_{0}+\delta_{1}}{\delta_{1}}, & \beta_{0}-\delta_{1} \leq \beta \leq \beta_{0} \\ \frac{\beta_{0}+\delta_{2}-\beta}{\delta_{2}}, & \beta_{0} \leq \beta \leq \beta_{0}+\delta_{2} \\ 0, & \text { elsewhere }\end{array}\right.$

Here $0<\delta_{1}<\beta_{0}, 0<\delta_{2}$ and $\beta_{0}$ are given fixed numbers. $\delta_{1}$ and $\delta_{2}$ are determined by the decision maker based on the given uncertainty. For each $\mathrm{T}$ and $\mathrm{T}_{1}$, let $\mathrm{G}_{\left(\mathrm{T}_{1}, \mathrm{~T}\right)}(\beta)=\mathrm{f}\left(\mathrm{T}_{1}, \mathrm{~T}\right)+\beta \mathrm{g}\left(\mathrm{T}_{1}, \mathrm{~T}\right), 0<\beta<1 \quad$ and $\mathrm{z}=\mathrm{G}_{\left(\mathrm{T}_{1}, \mathrm{~T}\right)}(\beta)$. Then $\beta=\frac{\mathrm{z}-\mathrm{f}\left(\mathrm{T}_{1}, \mathrm{~T}\right)}{\mathrm{g}\left(\mathrm{T}_{1}, \mathrm{~T}\right)} \geq 0$ if $\mathrm{z} \geq \mathrm{f}\left(\mathrm{T}_{1}, \mathrm{~T}\right)$. By the Extension Principle [19], We have the Following :

If $\mathrm{z}<\mathrm{f}\left(T_{1}, T\right)$, then $\mu_{\left.\mathrm{G}_{\left(\mathrm{T}_{1}, \mathrm{~T}\right)} \widetilde{\beta}\right)}(\mathrm{z})=0$.

If $\mathrm{z} \geq \mathrm{f}\left(T_{1}, T\right)$, then $\mu_{\left.\mathrm{G}_{\left(\mathrm{T}_{1}, T\right)} \widetilde{\mathrm{\beta}}\right)}(\mathrm{z})=\sup _{\beta \in G_{\left(T_{1}, T\right)}^{-1}(\mathrm{z})} \mu_{\widetilde{\beta}}(\beta)=\mu_{\widetilde{\beta}}\left(\frac{z-f\left(T_{1}, T\right)}{g\left(T_{1}, T\right)}\right)$

$$
=\left\{\begin{array}{cl}
\frac{z-f\left(T_{1}, T\right)-\left(\beta_{0}-\delta_{1}\right) g\left(T_{1}, T\right)}{\delta_{1} g\left(T_{1}, T\right)}, & c_{1} \leq z \leq c_{0} \\
\frac{\left(\beta_{0}+\delta_{2}\right) g\left(T_{1}, T\right)-z+f\left(T_{1}, T\right)}{\delta_{2} g\left(T_{1}, T\right)}, & c_{0} \leq z \leq c_{2} \\
0, & \text { elsewhere }
\end{array}\right.
$$

Where $c_{1}=f\left(T_{1}, T\right)+\left(\beta_{0}-\delta_{1}\right) g\left(T_{1}, T\right)$

$$
\begin{aligned}
& c_{0}=\mathrm{f}\left(\mathrm{T}_{1}, \mathrm{~T}\right)+\beta_{0} \mathrm{~g}\left(\mathrm{~T}_{1}, \mathrm{~T}\right) \\
& c_{2}=f\left(T_{1}, T\right)+\left(\beta_{0}+\delta_{2}\right) g\left(T_{1}, T\right)
\end{aligned}
$$

This $\mu_{\left.\mathrm{G}_{\left(\mathrm{T}_{1}, \mathrm{~T}\right)} \widetilde{\beta}\right)}(\mathrm{z})$ is the membership function of the fuzzy total cost $\mathrm{G}_{\left(\mathrm{T}_{1}, \mathrm{~T}\right)} \widetilde{(\beta)}$, for each $\mathrm{T}_{1}, \mathrm{~T}$ and $0<\delta_{1}<\beta_{0}, \delta_{2}>0$.

We find the centroid of $\mu_{\mathrm{G}_{\left(\mathrm{T}_{1}, \mathrm{~T}\right)}(\widetilde{\beta})}(\mathrm{z})$ as follows :

$$
\begin{gathered}
\int_{-\infty}^{\infty} \mu_{\left.\mathrm{G}_{\left(\mathrm{T}_{1}, \mathrm{~T}\right)} \widetilde{\beta}\right)}(\mathrm{z}) \mathrm{dz}=\frac{1}{\delta_{1} \mathrm{~g}\left(\mathrm{~T}_{1}, \mathrm{~T}\right)} \int_{c_{1}}^{c_{0}}\left\{z-f\left(T_{1}, T\right)-\left(\beta_{0}-\delta_{1}\right) g\left(T_{1}, T\right)\right\} d z \\
+\frac{1}{\delta_{2} \mathrm{~g}\left(\mathrm{~T}_{1}, \mathrm{~T}\right)} \int_{c_{0}}^{c_{2}}\left\{\left(\beta_{0}+\delta_{2}\right) \mathrm{g}\left(\mathrm{T}_{1}, \mathrm{~T}\right)-\mathrm{z}+\mathrm{f}\left(\mathrm{T}_{1}, \mathrm{~T}\right)\right\} d z \\
=\frac{\delta_{1}+\delta_{2}}{2} \mathrm{~g}\left(T_{1}, T\right)=\mathrm{J}_{1} \text { (say), }
\end{gathered}
$$

and $\int_{-\infty}^{\infty} z \mu_{\left.\mathrm{G}_{\left(\mathrm{T}_{1}, \mathrm{~T}\right)} \widetilde{\beta}\right)}(\mathrm{z}) \mathrm{dz}=\frac{1}{\delta_{1} \mathrm{~g}\left(\mathrm{~T}_{1}, \mathrm{~T}\right)} \int_{c_{1}}^{c_{0}}\left[z\left\{z-f\left(T_{1}, T\right)-\left(\beta_{0}-\delta_{1}\right) g\left(T_{1}, T\right)\right\}\right] d z$

$$
\begin{aligned}
& \quad+\frac{1}{\delta_{2} \mathrm{~g}\left(\mathrm{~T}_{1}, \mathrm{~T}\right)} \int_{c_{0}}^{c_{2}}\left[z\left\{\left(\beta_{0}+\delta_{2}\right) \mathrm{g}\left(\mathrm{T}_{1}, \mathrm{~T}\right)-\mathrm{z}+\mathrm{f}\left(\mathrm{T}_{1}, \mathrm{~T}\right)\right\}\right] d z \\
& =\frac{\delta_{1}+\delta_{2}}{2} \mathrm{~g}\left(T_{1}, T\right) \times\left\{f\left(T_{1}, T\right)+\beta_{0} g\left(T_{1}, T\right)+\frac{1}{3}\left(\delta_{2}-\delta_{1}\right) g\left(T_{1}, T\right)\right\} \\
& =\mathrm{J}_{2} \text { (say), }
\end{aligned}
$$

Therefore, the centroid of $\mu_{\mathrm{G}_{\left(\mathrm{T}_{1}, \mathrm{~T}\right)}(\widetilde{\beta})}(\mathrm{z})$ is

$\mathrm{N}\left(T_{1}, T, \delta_{1}, \delta_{2}\right)=\frac{\mathrm{J}_{2}}{\mathrm{~J}_{1}}=\left\{f\left(T_{1}, T\right)+\beta_{0} g\left(T_{1}, T\right)+\frac{1}{3}\left(\delta_{2}-\delta_{1}\right) g\left(T_{1}, T\right)\right\}$, 
Where $\mathrm{T}_{1}>0,0<\delta_{1}<\beta_{0}, 0<\delta_{2}$.

$\mathrm{N}\left(T_{1}, T, \delta_{1}, \delta_{2}\right)$ is the estimate of total profit in fuzzy sense. If $\delta_{1}=\delta_{2}$, then for $\beta=\beta_{0}$ equation 17 is equal to $\mathrm{N}\left(T_{1}, T, \delta_{1}, \delta_{2}\right)$.

\section{Numerical Example}

In this section, a numerical example is considered to illustrate the models. The following values of parameters are used in the example:

$\mathrm{s}=5, \mathrm{~K}=40, \mathrm{~h}=0.4, \mathrm{~d}=6, \mathrm{P}=50, \mathrm{P}_{1}=80, \pi=7, \beta=0.2, \gamma=4, \delta=0.3, \mathrm{a}=11, \mathrm{~b}=0.004, \beta_{0}=0.04, \quad \delta_{1}=$ $0.01, \delta_{2}=0.017$ in appropriate units.

For Crisp model, the optimal values are $\mathrm{TP}=278.2972, \mathrm{~T}_{1}=0.7935, \mathrm{~T}=1.0925$.

For fuzzy model, the optimal values are $\mathrm{TP}=288.6015, \mathrm{~T}_{1}=1.0920, \mathrm{~T}=1.3346$.

So the result shows that if the uncertainties are accounted for in appropriate manner the total profit per unit time TP would increase $3.7026 \%$, the cycle time $\mathrm{T}$ would $22.1630 \%$ and the time at which shortage started $\mathrm{T}_{1}$ would increase $37.6260 \%$.

\section{Sensitivity Analysis}

Sensitivity analysis depicts the extent to which the output of a model is affected by changes or errors in its input parameters. In this section, we examine the sensitivity of the total profit per unit time (TP), cycle time T and time at which shortage started $\mathrm{T}_{1}$ in the fuzzy model with respect to the changes in the fuzzy system parameters $\mathrm{s}, \mathrm{h}, \pi, \mathrm{a}, \mathrm{b}, \mathrm{K}, \delta, \beta, \gamma$. The sensitivity analysis is done by changing the value of each of the parameters by $-20 \%,-10 \%,+10 \%$ and $+20 \%$, taking one parameter at each time and keeping the remaining parameters unchanged. The results are shown in Table 1.

TABLE 1 : EFFECT OF CHANGES IN VARIOUS PARAMETERS OF THE INVENTORY

\begin{tabular}{|c|c|c|c|c|}
\hline \multirow[t]{2}{*}{ Parameter } & \multirow{2}{*}{$\begin{array}{l}\% \text { change in } \\
\text { parameter } \\
\text { values }\end{array}$} & \multicolumn{3}{|c|}{$\%$ change in } \\
\hline & & $\mathrm{T}_{1}^{*}$ & $\mathrm{~T}^{*}$ & $\mathrm{TP}^{*}$ \\
\hline \multirow[t]{4}{*}{$\mathrm{S}$} & -20 & -0.0310 & +1.0388 & +0.1135 \\
\hline & -10 & -0.0136 & +0.5053 & +0.0556 \\
\hline & +10 & +0.0100 & -0.4793 & -0.0536 \\
\hline & +20 & +0.0166 & -0.9348 & -0.1053 \\
\hline \multirow[t]{4}{*}{$\mathrm{h}$} & -20 & +0.3423 & +0.1170 & +0.1348 \\
\hline & -10 & +0.1713 & +0.0587 & +0.0673 \\
\hline & +10 & -0.1717 & -0.0593 & -0.0671 \\
\hline & +20 & -0.3438 & -0.1191 & -0.1341 \\
\hline \multirow[t]{4}{*}{$\pi$} & -20 & -0.0632 & +0.3929 & +0.0362 \\
\hline & -10 & -0.0312 & +0.1941 & +0.0179 \\
\hline & +10 & +0.0305 & -0.1893 & -0.0175 \\
\hline & +20 & +0.0603 & -0.3743 & -0.0347 \\
\hline \multirow[t]{4}{*}{$\mathrm{a}$} & -20 & +4.4422 & +6.7310 & -22.0087 \\
\hline & -10 & +2.0799 & +3.1035 & -11.0226 \\
\hline & +10 & -1.6942 & -2.4674 & +10.0468 \\
\hline & +20 & -3.8469 & -5.4014 & 22.1311 \\
\hline \multirow[t]{4}{*}{$\mathrm{b}$} & -20 & +0.0275 & -0.0692 & -0.0334 \\
\hline & -10 & +0.0136 & -0.0347 & -0.0167 \\
\hline & +10 & -0.0135 & +0.0348 & +0.0168 \\
\hline & +20 & -0.0268 & +0.0698 & +0.0335 \\
\hline \multirow[t]{4}{*}{$\mathrm{K}$} & -20 & -3.7175 & -5.3471 & +1.8668 \\
\hline & -10 & -2.0488 & -2.9777 & +1.0541 \\
\hline & +10 & +1.8801 & +2.8018 & -1.0241 \\
\hline & +20 & +3.6190 & +5.4542 & -2.0214 \\
\hline \multirow[t]{4}{*}{$\beta$} & -20 & 0.0000 & 0.0000 & 0.0000 \\
\hline & -10 & 0.0000 & 0.0000 & 0.0000 \\
\hline & +10 & 0.0000 & 0.0000 & 0.0000 \\
\hline & +20 & 0.0000 & 0.0000 & 0.0000 \\
\hline \multirow[t]{4}{*}{$\gamma$} & -20 & +2.2194 & +2.0574 & -0.1876 \\
\hline & -10 & +0.8361 & +0.7799 & -0.0746 \\
\hline & +10 & -0.9177 & -0.8636 & +0.0882 \\
\hline & +20 & -1.6650 & -1.5739 & +0.1655 \\
\hline
\end{tabular}




\begin{tabular}{|l|l|l|l|l|}
\hline$\delta$ & -20 & -0.3709 & +2.3240 & +0.2120 \\
& -10 & -0.1736 & +1.0824 & +0.0995 \\
& +10 & +0.1539 & -0.9520 & -0.0886 \\
& +20 & +0.2915 & -1.7959 & -0.1679 \\
\hline
\end{tabular}

It is seen that

(i) $\mathrm{T}^{*}, \mathrm{TP}^{*}$ are moderately sensitive while $\mathrm{T}_{1}^{*}$ is less sensitive due to the changes in the value of the shortage cost $s$, the opportunity cost $\pi$ and the backlogging parameter $\delta$.

(ii) $\mathrm{T}^{*}, \mathrm{TP}^{*}$ and $\mathrm{T}_{1}^{*}$ are all moderately sensitive to changes in the holding cost $\mathrm{h}$ whereas $\mathrm{T}^{*}, \mathrm{TP}^{*}$ and $\mathrm{T}_{1}^{*}$ are not at all sensitive for changes in the deterioration parameter $\beta$.

(iii) $\mathrm{T}^{*}, \mathrm{TP}^{*}$ are not generally much sensitive for changes in the demand parameter $\mathrm{b}$; $\mathrm{T}_{1}^{*}$ is comparatively more sensitive to errors in $b$.

(iv) $\mathrm{TP}^{*}$ is slightly sensitive to changes in the other deterioration parameter $\gamma$ and $\mathrm{T}_{1}^{*}, \mathrm{~T}^{*}$ are more sensitive for changes in $\gamma$.

(v) $\mathrm{T}^{*}, \mathrm{TP}^{*}$ and $\mathrm{T}_{1}^{*}$ are very sensitive due to the changes in the other demand parameter a and the ordering cost $\mathrm{K}$.

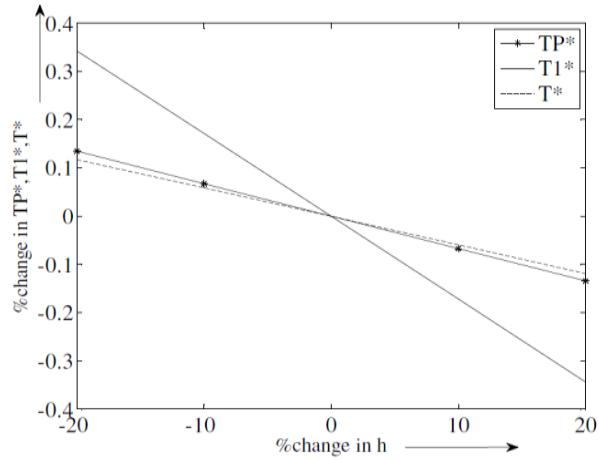

Fig. 2 The Effect of change in the total profit TP*,time at which shortage started

$\mathrm{T}_{1}$ *and cycle time $\mathrm{T}^{*}$ due to change in holding cost $h$.change in opportunity $\cos t \pi$.

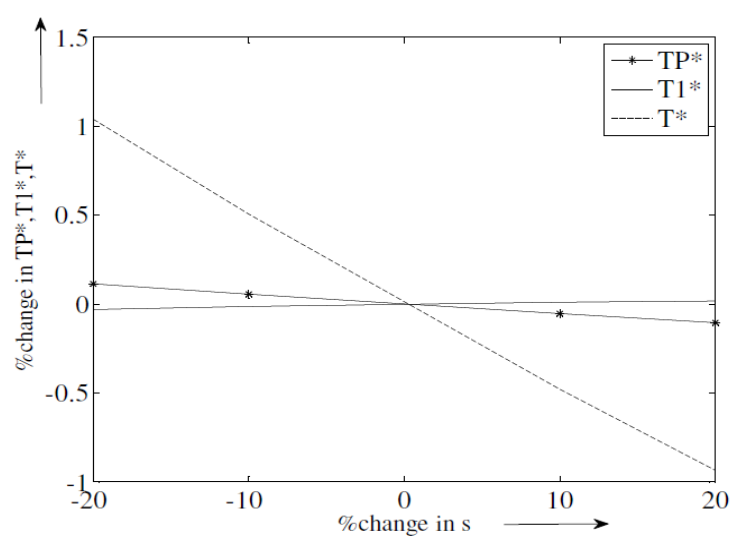

Fig. 4 The Effect of change in the total profit $\mathrm{TP}^{*}$, time at which shortage started $\mathrm{T}_{1} *$ and cycle time $\mathrm{T}^{*}$ due to change in shortage cost $\mathrm{s}$.

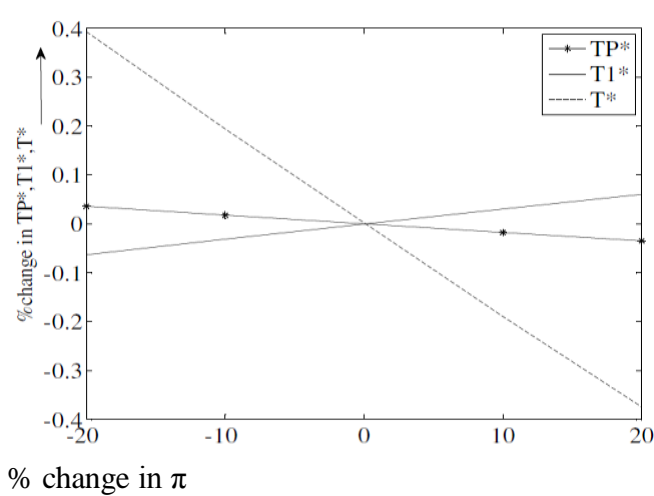

Fig. 3 The Effect of change in the total profit $\mathrm{TP}^{*}$, time at which shortage started $\mathrm{T}_{1} *$ and cycle time $\mathrm{T}^{*}$ due to

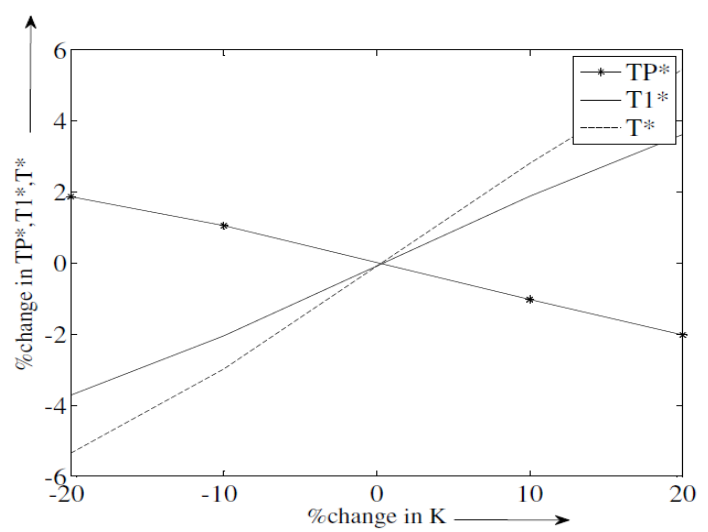

Fig.5 The Effect of change in the total profit TP*, time at which shortage started $\mathrm{T}_{1} *$ and cycle time $\mathrm{T}^{*}$ due to change in ordering cost $\mathrm{K}$. 


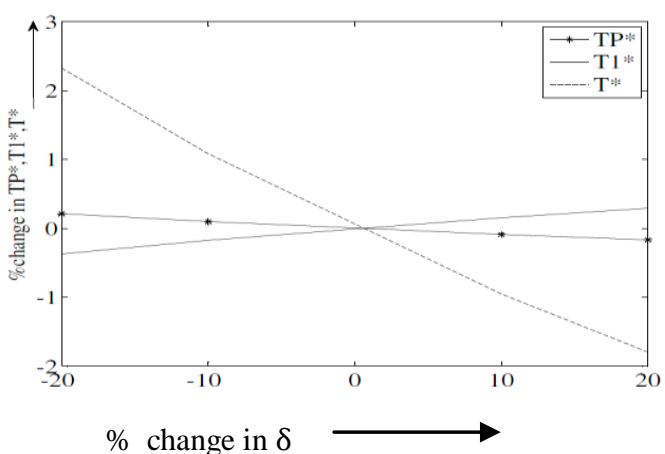

Fig. 6 The Effect of change in the total profit TP*,time at which shortage started $\mathrm{T}_{1}$ *and cycle time $\mathrm{T}^{*}$ due to change in backlogging parameter $\delta$.

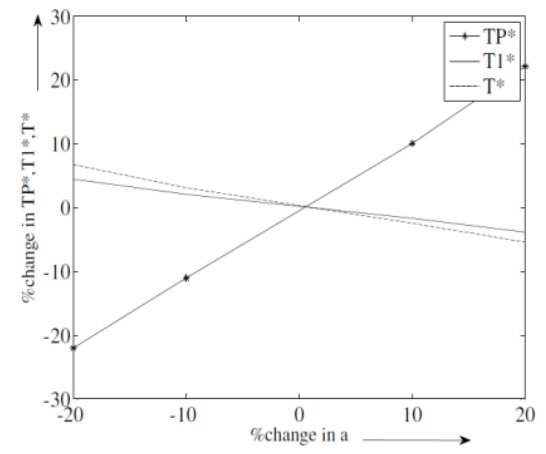

Fig. 7 The Effect of change in the total profit $\mathrm{TP}^{*}$, time at which shortage started $\mathrm{T}_{1} *$ and cycle time $\mathrm{T}^{*}$ due to change in demand parameter a .

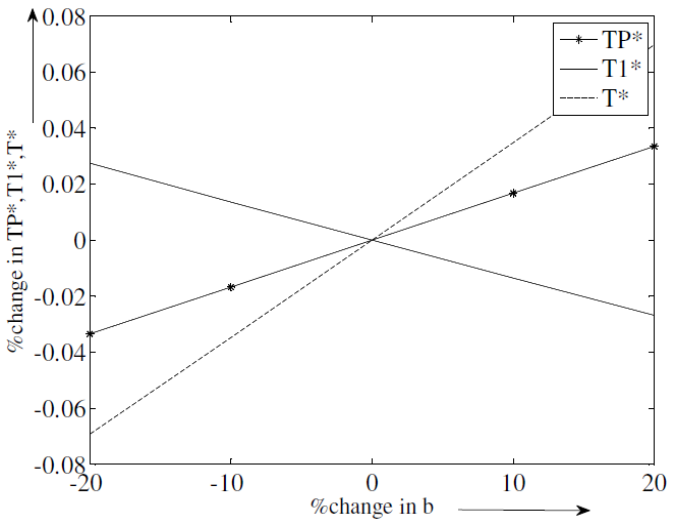

Fig. 8 The Effect of change in the total profit $\mathrm{TP} *$,time at which shortage started $\mathrm{T}_{1} *$ and cycle time $\mathrm{T}^{*}$ due to change in demand parameter $\mathrm{b}$.

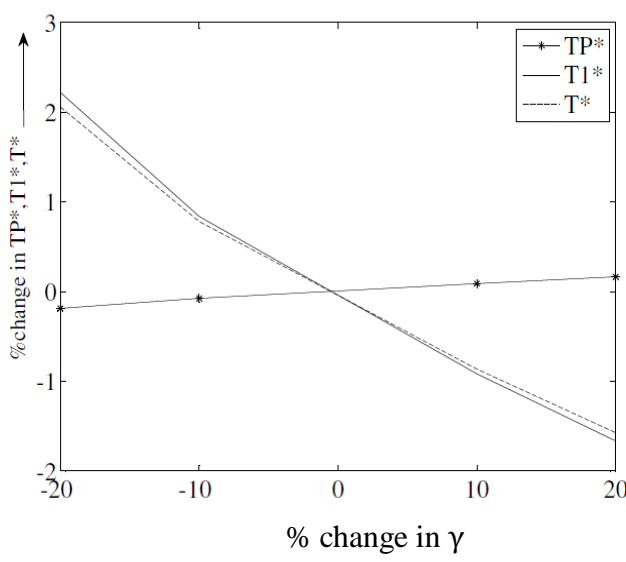

Fig. 9 The Effect of change in the total profit TP*, time at which shortage started $\mathrm{T}_{1} *$ and cycle time $\mathrm{T}^{*}$ due to change in deterioration parameter $\gamma$.

\section{Conclusion}

In this paper, we have presented an inventory model with weibull deteriorating items with timedependent demand where unsatisfied demand is partially backlogged and then the deterioration rate is assumed as fuzzy number instead of crisp or probabilistic in nature. We have considered the nature of the parameter as fuzzy to make the inventory model more realistic. Numerically we tried to compare the crisp model with fuzzy model. Lastly, to study the effect of the decision variables on changes of different parameters, a sensitivity analysis is also produced.

\section{References}

[1] T.M. Whitin. "Theory of Inventory Management". Princeton University Press, New Jersey, USA, 1957.

[2] U. Dave and L.K. Patel. "Policy inventory model for deteriorating items with time proportional demand". Journal of theoperati onal Research Society, 32(1), 1981, 137-142.

[3] R.H. Hollier and K.L. Malc. "Inventory replenishment policies for deteriorating itemsin a declining market". International Journal of production Research, 21(7), 1983, 813-826.

[4] H. Xu and H. Wang. "Optimal inventory policy for perishable items with time proportional demand". IIETransactions, 24(5), $1992,105-110$.

[5] A. Goswami and K.S. Chaudhuri. "An EOQ model for deteriorating items with shortages and a linear trend in demand". Journal of the operational Research Society, 42(12), 1991,1105-1110.

[6] T.Chakrabarti. "An EOQ model for deteriorating items with a linear trend in demand and shortages in all cycles". International Journal of Production Economics ,49, 1997,205- 213.

[7] T. Chakrabarti. "An EOQ model for items with Weibull distribution deterioration ,shortages and trended demand: An extension of Phillip's model". International Journal of Computers and Operations Research ,25(7/8), 1998.

[8] H.J. Chang and C.Y. Dye. "An EOQ model for deteriorating items with time-varying demand and partial backlogging”. Journal of the Operational Research Society, 50(11),1999,1176-1182.

[9] J.T. Teng, M.S. Chern and H.L. Yang. "An optimal recursive method for various inventory replenishment model with increasing demand and shortages". NavalResearch Logistics, 44(10),1997,791-806. 
[10] M. Valliathal and R. Uthayakumar. "An EOQ model for perishable items under stock and time-dependent selling rate with shortages". ARPN Journal of Engineering and Applied Sciences,4(8),2009,8-14.

[11] H. Yan and T. Cheng. "Optimal production stopping and restarting times for an EOQmodel with deteriorating Items". Journal of the Operation Research Society, 49(12), 1998,1288-1295.

[12] S.K. Goyal and B.C. Giri. "Recent trends in modeling of deteriorating inventory".European Journal of Operational Research, 34(1),2001, 1-16.

[13] T.K. Roy and M. Maiti. "A fuzzy EOQ model with demand dependent unit cost under limited storage capacity". European Journal of Operation Research, 99,1997,425-432.

[14] S.C. Chang, J.S. Yao and H.M. Lee. "Economic reorder point for fuzzy backorder quantity". European Journal of Operation Research, 109, 1998,183-202.

[15] H.M. Lee and J.S. Yao. "Economic production quantity for fuzzy demand quantity and fuzzy productionquantity".European Journal of Operation Research, 109, 1998,203-211.

[16] D.C. Lin and J.S. Yao. "Fuzzy economic production for production inventory". Fuzzy Sets and Systems, 111, 2000,.465-495.

[17] S. De and A. Goswami. "A replenishment policy for items with finite production rate and fuzzydeteriorationrate".Opsearch, 38 , $2001,419-430$

[18] G.C. Mahata and A. Goswami. "Fuzzy EOQ Models foe Deteriorating Items with Stock Dependent Demand \& Nonlinear Holding Costs". International Journal of Mathematical and Computer Science, 5(2), 2009,94-98.

[19] H. J. Zimmerman. "Fuzzy set theory and its applications". Kluwer Academic Press, 2nd Edition, 1991.

[20] A.KaufmannandM.M.Gupta."Introductiontofuzzyarithmetic theory an applications".VonNostrandReinhold,Newyork,1992. 